\title{
FDG-PET as an independent biomarker for Alzheimer's biological diagnosis: a longitudinal study
}

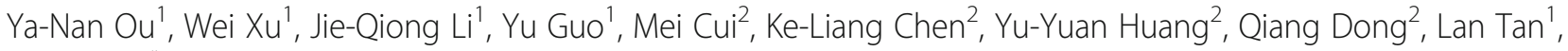
Jin-Tai $Y u^{2^{*}}$ (D) and on behalf of Alzheimer's Disease Neuroimaging Initiative

\begin{abstract}
Background: Reduced ${ }^{18}$ F-fluorodeoxyglucose-positron emission tomography (FDG-PET) brain metabolism was recognized as a biomarker of neurodegeneration in the recently proposed ATN framework for Alzheimer's disease (AD) biological definition. However, accumulating evidence suggested it is an independent biomarker, which is denoted as " $F$ " in the very study.

Methods: A total of 551 A+T+ individuals from the Alzheimer's Disease Neuroimaging Initiative database were recruited and then further divided into four groups based on the biomarker positivity as $132 \mathrm{~A}+\mathrm{T}+\mathrm{N}-\mathrm{F}-, 102$ $\mathrm{A}+\mathrm{T}+\mathrm{N}-\mathrm{F}+, 113 \mathrm{~A}+\mathrm{T}+\mathrm{N}+\mathrm{F}-$, and $204 \mathrm{~A}+\mathrm{T}+\mathrm{N}+\mathrm{F}+$. Frequency distributions of the groups were compared, as well as the clinical progression [measured by the longitudinal changes in cognition and brain structure, and mild cognitive impairment $(\mathrm{MCl})$ to $A D$ dementia conversion] between every pair of $\mathrm{F}+$ and $\mathrm{F}$ - groups.

Results: The prevalence of $\mathrm{A}+\mathrm{T}+\mathrm{N}+\mathrm{F}+$ profile was $66.24 \%$ in clinically diagnosed AD dementia patients; similarly, the majority of individuals with reduced FDG-PET were AD dementia subjects. Among the 551 individuals that included, 537 had at least one follow-up (varied from 1 to 8 years). Individuals in F+ groups performed worse and dropped faster in Mini-Mental State Examination scale and had faster shrinking middle temporal lobe than those in $\mathrm{F}$ - groups (all $p<0.05$ ). Moreover, in $\mathrm{MCl}$ patients, reduced FDG-PET exerted 2.47 to 4.08 -fold risk of AD dementia progression compared with those without significantly impaired FDG-PET (both $p<0.001$ ).
\end{abstract}

Conclusions: Based on the analyses, separating FDG-PET from "N" biomarker to build the ATN(F) system is necessary and well-founded. The analysis from this study could be a complement to the original ATN framework for AD's biological definition.

Keywords: ${ }^{18}$ F-Fluorodeoxyglucose positron emission tomography (FDG-PET), Alzheimer's disease, ATN profile, Biomarker

\section{Background}

Recently, the 2018 National Institute on Aging-Alzheimer's Association (NIA-AA) proposed a research framework of a descriptive classification scheme for biomarkers used in Alzheimer's disease (AD) research [1]. In this framework, "A" biomarkers refer to amyloidosis [abnormal tracer retention on amyloid positron emission tomography (PET)

\footnotetext{
* Correspondence: jintai_yu@fudan.edu.cn

${ }^{2}$ Department of Neurology and Institute of Neurology, Huashan Hospital, Shanghai Medical College, Fudan University, 12th Wulumuqi Zhong Road Shanghai 200040, China

Full list of author information is available at the end of the article
}

imaging and low $\beta$-amyloid $(\mathrm{A} \beta)$ concentration in the cerebrospinal fluid (CSF)]; "T" biomarkers, the value of increased CSF phosphorylated tau (P-tau) and cortical tau PET; and "N," biomarkers of neurodegeneration or neural injury [higher CSF total tau (T-tau), diminished ${ }^{18} \mathrm{~F}$-fluorodeoxyglucose (FDG)-PET and atrophic brain structures in magnetic resonance image (MRI)] [1]. An individual can be biologically diagnosed as $\mathrm{AD}$ when he/she present with both biomarker evidences of $\mathrm{A} \beta$ and pathological tau $(\mathrm{A}+\mathrm{T}+)$. This framework treats $\mathrm{AD}$ as a continuum and introduces different pathologic biomarkers to weigh the diagnostic probability of the disease $[2,3]$. 
FDG-PET is extensively and increasingly used to support the clinical diagnosis in the examination of patients with suspected neurodegenerative disorders, especially $\mathrm{AD}[4,5]$. It reflects both cumulative loss of neuropil, loss of synapse, and functional impairment of the neurons. Lower FDG-PET was regarded as a signal of neuronal hypometabolism due to neurodegeneration and was labeled as "N" biomarkers as the research framework defined. However, a recent study showed it reflects the consumption of glucose by astrocytes, rather than by neurons [6]. Moreover, there is a literature that has demonstrated that diminished FDG brain uptake by PET might be a biomarker tracking vascular, more precise, blood-brain barrier (BBB) transport, abnormality [7]. Based upon this hypothesis, an analysis was conducted in the Alzheimer's Disease Neuroimaging Initiative (ADNI) prospective clinical cohort to explore the necessity and feasibility of making FDG-PET function as a separate biomarker, which is independent from "N" biomarker and labeled as " $\mathrm{F}$ " representing FDG hypometabolism in $\mathrm{A}+\mathrm{T}+$ individuals. This refinement enables an independent identification of non-specific neurodegenerative biomarkers to be independent, leading to a more precise understanding of the biological underpinnings of brain aging.

\section{Methods}

\section{Participants}

Data used in the preparation for this article were obtained from the ADNI database (http://adni.loni.usc. edu) $[8,9]$. Individuals were included in our study if they underwent CSF $A \beta(A)$, CSF P-tau (T), CSF T-tau (N), and FDG-PET (F) examinations at baseline. In an alternative analysis, we used adjusted hippocampal volume (HVa) to represent "N." Individuals were classified into four groups: $\mathrm{CN}, \mathrm{MCI}$, which can be further divided into stable MCI (sMCI, MCI remained stable during at least 2 years follow-up) and progressive MCI (pMCI, who progressed from $\mathrm{MCI}$ to $\mathrm{AD}$ dementia during at least 2 years follow-up) and $\mathrm{AD}$ dementia. Patients with $\mathrm{AD}$ dementia fulfilled the National Institute of Neurological and Communicative Disorders and Stroke-Alzheimer's Disease and Related Disorders Association criteria for probable AD, had Mini-Mental State Examination (MMSE) scores of 20 to 26, and had Clinical Dementia Rating (CDR) global scores of between 0.5 and 1.0. MCI patients had MMSE scores of 24 or higher, a CDR score of 0.5 , objective memory loss tested by the delayed recall of the Wechsler Memory Scale logical memory II [ $>1$ standard deviation (SD) below the normative mean], preserved activities of daily living, and absence of dementia. Controls had MMSE scores of 24 or higher and a CDR global score of 0 . Individuals with subjective memory complaints at baseline were not excluded from the analyses. Instead, they were included within the $\mathrm{CN}$ group.

\section{ATN(F) measurements}

CSF samples were frozen on dry ice within $1 \mathrm{~h}$ after collection by lumbar puncture and shipped overnight on dry ice to the ADNI Biomarker Core laboratory. Aliquots $(0.5 \mathrm{~mL})$ were prepared from these samples and stored in barcode-labeled polypropylene vials at $-80^{\circ} \mathrm{C}$. A $\beta$ positive $(\mathrm{A}+)$ subjects were those who had CSF $\mathrm{A} \beta$ concentration levels $\leq 192 \mathrm{pg} / \mathrm{ml}$ [10]. Similarly, P-taupositive $(\mathrm{T}+)$ was defined as a score above a cutoff point of $23 \mathrm{pg} / \mathrm{ml}$ [10]. T-tau-positive $(\mathrm{T}+)$ individuals were those who had CSF T-tau concentration levels $\geq 93 \mathrm{pg} / \mathrm{ml}$ [10]. We adjusted the hippocampal volume for total intracranial volume (TIV) using the following equation: $\mathrm{HVa}=\mathrm{Raw} \mathrm{HV}-b$ (eTIV - Mean eTIV), where $b$ indicates the regression coefficient when $\mathrm{HV}$ is regressed against eTIV [11]. We defined HVa-positive $(\mathrm{N}+)$ and negative $(\mathrm{N}-)$ subjects based on a cutoff point of $6723 \mathrm{~mm}^{3}$ [11].

The FDG-PET images (via averaging counts of angular, temporal, and posterior cingulate regions) in this study were pre-processed using a series of steps to mitigate inter-scanner variability and obtain FDG-PET data with a uniform spatial resolution and intensity range for further analysis. Preprocessing steps included dynamic co-registration of images acquired in consecutive time frames, averaging, reorientation along the anteriorposterior commissure and filtering with a scannerspecific filter function to produce images of a uniform isotropic resolution of $8 \mathrm{~mm}$ full width at half maximum Gaussian kernel. A cutoff value equal to 1.21 was used to divide subjects into two groups: FDG-PET-negative subjects (F-) with level $>1.21$ and FDG-PET-positive subjects $(\mathrm{F}+)$ with level $\leq 1.21[10]$.

\section{Neuroimaging and cognition}

Structural MRI was performed using a Siemens Trio 3.0 $\mathrm{T}$ scanner or Vision $1.5 \mathrm{~T}$ scanner (Siemens, Erlangen, Germany). Regional volume estimates were processed using Free-surfer software package version 4.3 and 5.1 image processing framework for the 1.5 and $3.0 \mathrm{~T}$ MRI images, respectively. We used middle temporal lobe (MTL) volume, entorhinal cortex (EC) thickness, and ventricular volume for measures of brain structure. General cognition was assessed by MMSE, Rey Auditory Verbal Learning Test (RAVLT)-immediate, and RAVLTdelayed recall scales.

\section{Statistical analysis}

We adopted a two-step analysis in our report. Firstly, based on the cutoff thresholds of the four biomarkers, we dichotomized each biomarker category as either 
normal (-) or abnormal $(+)$, which resulted in four different biomarker group combinations, including $\mathrm{A}+\mathrm{T}+\mathrm{N}-\mathrm{F}-, \mathrm{A}+\mathrm{T}+\mathrm{N}-\mathrm{F}+, \mathrm{A}+\mathrm{T}+\mathrm{N}+\mathrm{F}-$, and $\mathrm{A}+\mathrm{T}+\mathrm{N}+\mathrm{F}+$. The frequency distributions of the four clinical cognitive diagnosis and four ATN(F) profiles among different groups were summarized in the histogram. Tests of intergroup differences were performed using the chi-square analysis for frequencies or one-way analysis of variance and post hoc analysis for continuous measures. Categorical variables are presented as numbers (percents) and continuous variables as means \pm SDs. Cognitive decline and brain atrophy over time were compared $(\mathrm{A}+\mathrm{T}+\mathrm{N}-\mathrm{F}-$ vs $\mathrm{A}+\mathrm{T}+\mathrm{N}-\mathrm{F}+$ and $\mathrm{A}+\mathrm{T}+\mathrm{N}+\mathrm{F}-$ vs $\mathrm{A}+\mathrm{T}+\mathrm{N}+\mathrm{F}+$ and $\mathrm{A}+\mathrm{T}+\mathrm{N}+\mathrm{F}-$ vs $\mathrm{A}+\mathrm{T}+\mathrm{N}-\mathrm{F}+$ ) using linear mixed-effects models. Estimates with corresponding 95\% confidence intervals (CIs) were obtained using a parametric bootstrap method in the arm package with 10,000 replicates. Analyses for the cognitive decline were adjusted for age, gender, $A P O E \varepsilon 4$, and years of education. Analyses for brain atrophy were adjusted for age, gender, $A P O E \varepsilon 4$, and total intracranial volume. Each clinical outcome measurement was log-transformed so that estimated change could be interpreted on an annual percentage scale. Unadjusted Kaplan-Meier (KM) analysis with the log-rank test to determine the progression from $\mathrm{MCI}$ to $\mathrm{AD}$ dementia was performed. Time-to-event was defined as the time from baseline $\mathrm{MCI}$ to $\mathrm{AD}$ dementia onset (with the end of study time or dropout as censor points). Additionally, the multivariate Cox proportional hazard model adjusted for baseline age, gender, educational level, and $A P O E \varepsilon 4$ status was conducted. Next, we compared clinical progression (measured by longitudinal cognitive/brain structure changes and $\mathrm{MCI}$ to $\mathrm{AD}$ dementia conversion) in the separate CSF T-tau (+), HVa (+), and FDG-PET (+) subgroups.

Statistical significance was defined as $p<0.05$ for all analyses. Statistical analyses were performed using $\mathrm{R}$ (version 3.5.1) and IBM SPSS Statistics 23.

\section{Results}

\section{Basic characteristics and inter-group comparisons}

Table 1 summarizes the basic demographic, clinical, psychometric, and CSF biomarker characteristics of our study population ( $n=551$, including $98 \mathrm{CN}, 296 \mathrm{MCI}$, and 157 AD dementia). The study population had a female proportion of 38\%, an age range from 55 to 90 years old at baseline (mean $\pm \mathrm{SD}=73.9 \pm 7.2$ ), education of $15.9 \pm 2.8$ years, and an $A P O E$ \&4 positive percentage of $67 \%$. The difference in age between $\mathrm{F}+$ and $\mathrm{F}-$ groups did not reach statistical significance (Table 1, Fig. 1a). F- groups had a relatively greater female proportion and this difference between $\mathrm{F}+$ and $\mathrm{F}$ - groups did not reach significance (Table 1, Fig. 1b). The difference in $A P O E$ \&4 positive between $\mathrm{N}-\mathrm{F}-$ group and $\mathrm{N}-\mathrm{F}+$ group reached statistical significance $(p=0.049$; Fig. 1c) with a higher proportion of $A P O E \& 4$ carrier subjects in the $\mathrm{F}+$ group. Overall, the $\mathrm{A}+\mathrm{T}+\mathrm{N}+\mathrm{F}+$ group had the highest proportion of $A P O E \varepsilon 4$ carrier subjects (74.02\%; Table 1). Cognitive performances

Table 1 Characteristics of participants by ATN(F) biomarker classification

\begin{tabular}{|c|c|c|c|c|}
\hline Characteristics & $\mathrm{A}+\mathrm{T}+\mathrm{N}-\mathrm{F}-$ & $\mathrm{A}+\mathrm{T}+\mathrm{N}-\mathrm{F}+$ & $\mathrm{A}+\mathrm{T}+\mathrm{N}+\mathrm{F}-$ & $\mathrm{A}+\mathrm{T}+\mathrm{N}+\mathrm{F}+$ \\
\hline$n$ & 132 & 102 & 113 & 204 \\
\hline Age (years) & $73.21 \pm 6.08$ & $74.46 \pm 7.38$ & $74.09 \pm 7.44$ & $74.02 \pm 7.59$ \\
\hline Female (\%) & $59(45 \%)$ & $34(33 \%)$ & $63(56 \%)$ & $92(45 \%)$ \\
\hline Educational level (years) & $16.31 \pm 2.35$ & $16.23 \pm 2.89$ & $15.57 \pm 2.69$ & $15.70 \pm 2.94$ \\
\hline APOE \&4 positive (\%) & $77(58 \%)$ & $64(63 \%)$ & $72(64 \%)$ & $151(74 \%)$ \\
\hline \multicolumn{5}{|l|}{ Cognitive score } \\
\hline MMSE & $28.21 \pm 1.87$ & $26.31 \pm 2.56$ & $27.62 \pm 2.17$ & $25.06 \pm 2.89$ \\
\hline RAVLT-immediate recall & $37.98 \pm 10.58$ & $29.81 \pm 10.22$ & $35.29 \pm 9.62$ & $26.16 \pm 9.87$ \\
\hline RAVLT-delayed recall & $3.48 \pm 4.02$ & $3.76 \pm 4.13$ & $3.51 \pm 4.02$ & $3.56 \pm 4.05$ \\
\hline \multicolumn{5}{|l|}{ Brain structure } \\
\hline MTL volume $\left(\mathrm{mm}^{3}\right)$ & $20,603.68 \pm 2852.81$ & $19,230.37 \pm 2999.68$ & $20,078.17 \pm 2789.14$ & $17,863.85 \pm 2891.62$ \\
\hline EC thickness (mm) & $3724.40 \pm 635.16$ & $3237.51 \pm 715.711$ & $3548.83 \pm 738.51$ & $3117.98 \pm 724.23$ \\
\hline Ventricular volume $\left(\mathrm{mm}^{3}\right)$ & $36,744.74 \pm 18,700.67$ & $55,002.57 \pm 23,690.36$ & $32,262.09 \pm 18,079.57$ & $42,955.53 \pm 20,601.77$ \\
\hline CSF A $\beta(p g / m l)$ & $142.71 \pm 26.92$ & $134.03 \pm 25.24$ & $136.06 \pm 20.82$ & $131.30 \pm 22.54$ \\
\hline CSF P-tau (pg/ml) & $40.60 \pm 15.28$ & $41.69 \pm 17.18$ & $58.35 \pm 22.56$ & $62.99 \pm 30.94$ \\
\hline CSF T-tau (pg/ml) & $67.05 \pm 16.43$ & $70.81 \pm 15.45$ & $142.66 \pm 46.12$ & $154.35 \pm 55.96$ \\
\hline FDG-PET & $1.34 \pm 0.09$ & $1.09 \pm 0.09$ & $1.33 \pm 0.09$ & $1.07 \pm 0.10$ \\
\hline
\end{tabular}

Categorical variables are reported as numbers and percentages; continuous variables are reported as means \pm SDs

Abbreviations: $n$ number, SD standard deviation, MMSE Mini-Mental State Examination, RAVLT Rey Auditory Verbal Learning Test, MTL middle temporal lobe, EC entorhinal cortex, CSF cerebrospinal fluid, $A \beta \beta$-amyloid, $P$-tau phosphorylated-tau, $T$-tau total-tau, FDG-PET ${ }^{18}$ F-fluorodeoxyglucose-positron emission tomography 

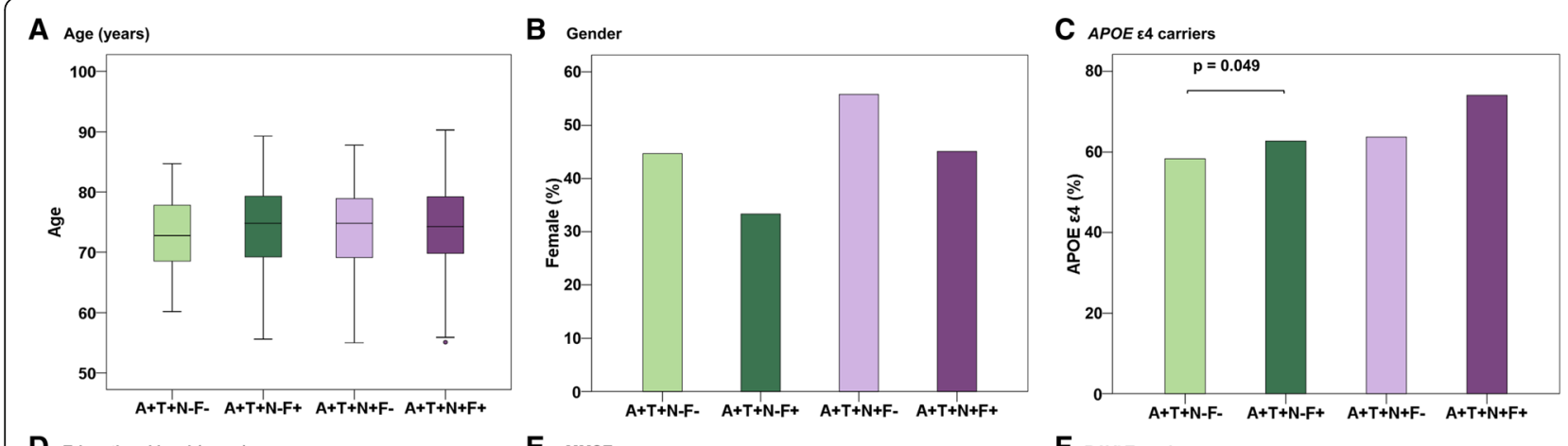

E MMSE score
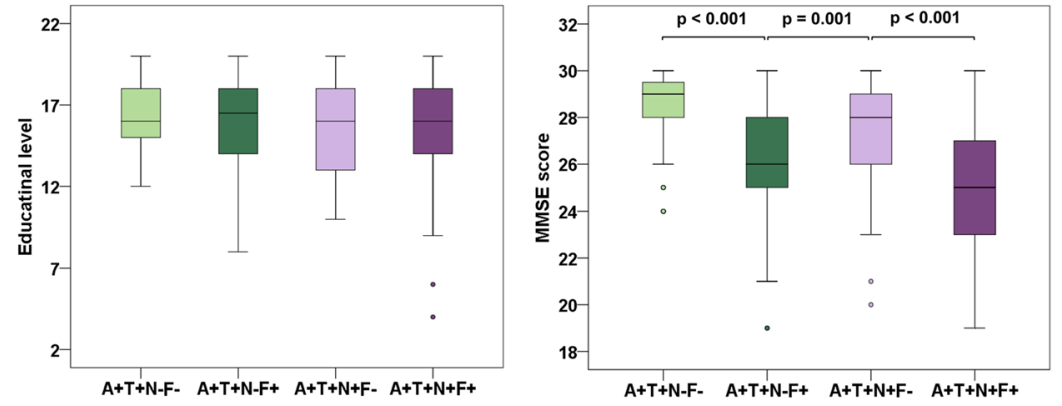

F RAVLT-total score
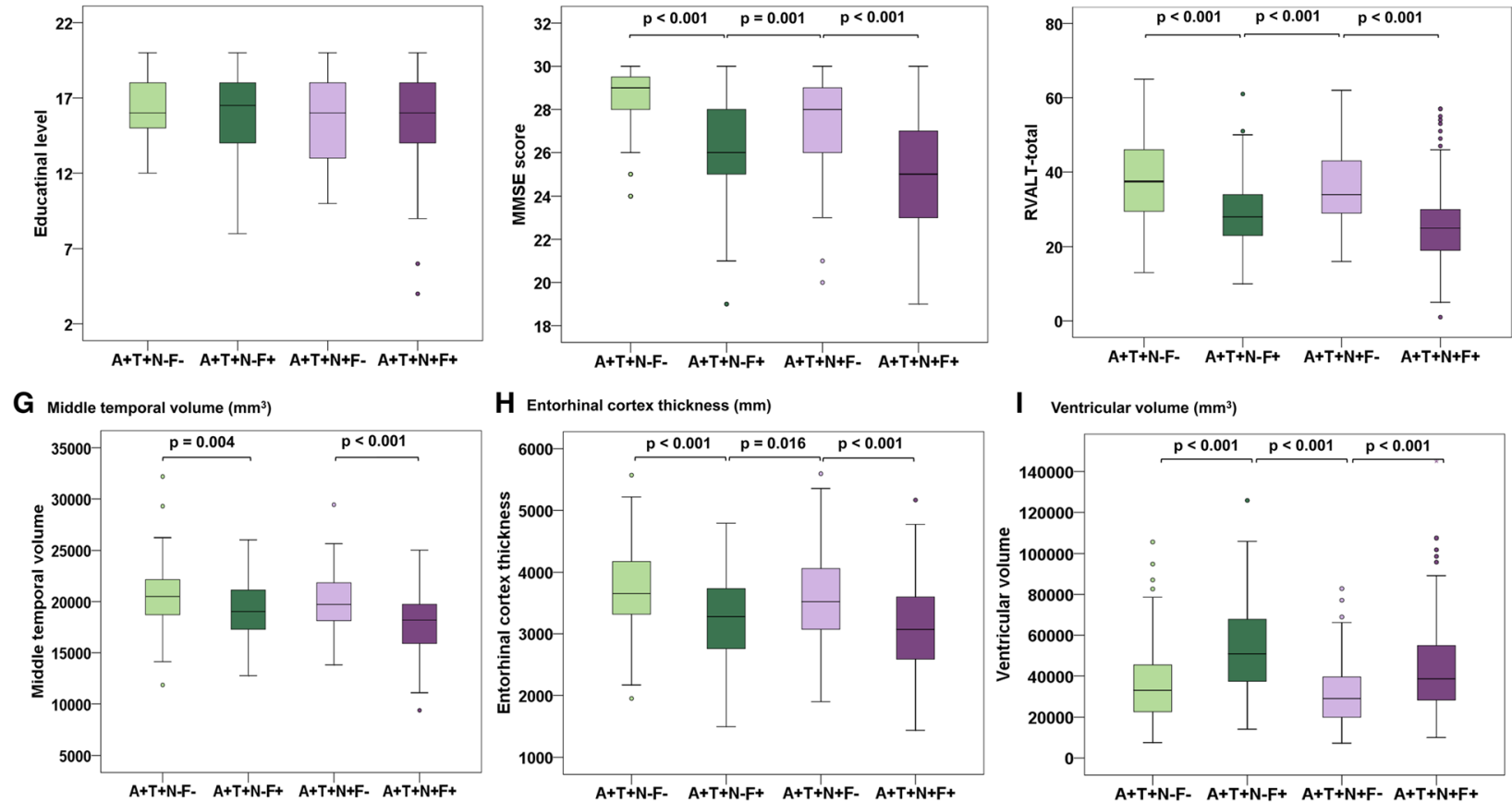

I Ventricular volume $\left(\mathrm{mm}^{3}\right)$

Fig. 1 Plots of ATN(F) group characteristics. Box plots of continuous variables and bar charts summarized percentages of categorical variables from Table 1. As illustrated in Table 1, the four groups are arranged left-right hierarchically on the basis of $A+T+$, then the differences between $\mathrm{F}$ - vs $\mathrm{F}+$ on the basis of $\mathrm{N}$ - and $\mathrm{N}+$ were demonstrated. Significant $p$ values of comparisons of every pair of F+ vs F- subgroups were depicted at the top of each figure. Abbreviations: MMSE, Mini-Mental State Examination; RAVLT-total, Rey Auditory Verbal Learning Test-immediate-total

also differed to a great degree among groups (all $p<0.001$; Table 1, Fig. 1e, f) with lower scores on MMSE and RAVLT-immediate in positive groups (lower scores represent worse cognitive function). Brain structures (MTL volume and EC thickness) significantly differed between groups, and they were smaller in $\mathrm{F}+$ groups compared with $\mathrm{F}$ - groups (all $p$ values $<0.05$; Table 1 , Fig. $1 \mathrm{~g}$, h) except for MTL volume in $\mathrm{A}+\mathrm{T}+\mathrm{N}-\mathrm{F}+$ and $\mathrm{A}+\mathrm{T}+\mathrm{N}+\mathrm{F}-$ groups. However, the volume of ventricles in $\mathrm{F}+$ groups was larger than that in $\mathrm{F}-$ groups (all $p$ values $<0.001$; Fig. 1i).

The alternative analysis was also performed using $\mathrm{HVa}$ instead of CSF T-tau as the $\mathrm{N}$ measure (Additional file 1 and Additional file 2). The population size for this analysis ( $n=493$, including $90 \mathrm{CN}, 260 \mathrm{MCI}$, and $143 \mathrm{AD}$ dementia; $140 \mathrm{~A}+\mathrm{T}+\mathrm{N}-\mathrm{F}-, 88 \mathrm{~A}+\mathrm{T}+\mathrm{N}-\mathrm{F}+, 73 \mathrm{~A}+\mathrm{T}+\mathrm{N}+\mathrm{F}-$, and $192 \mathrm{~A}+\mathrm{T}+\mathrm{N}+\mathrm{F}+$ ) was smaller. There was high consistency between the two analyses using HVa and CSF T-tau separately. The two analyses had similarly significant differences in cognitive scores, EC thickness, and ventricular volume in both comparisons $-\mathrm{N}-\mathrm{F}+$ vs $\mathrm{N}-\mathrm{F}-$ and $\mathrm{N}+\mathrm{F}+$ vs $\mathrm{N}+\mathrm{F}-$ (all $p$ values $<0.05$ ). However, no significant differences were found between the $\mathrm{N}-\mathrm{F}+\mathrm{vs} \mathrm{N}+\mathrm{F}-$ groups in all of the cognitive and brain structure measures except for EC thickness. This alternative analysis also found that only in the $\mathrm{N}+$ category the volume of MTL in the $\mathrm{F}+$ group was significantly lower than that in the F- group $(p<0.001)$.

\section{Frequency distributions of cognitive diagnosis and ATN(F) profiles}

The frequency distributions of clinical cognitive diagnosis among the four ATN(F) profiles and the frequency distributions of $\mathrm{ATN}(\mathrm{F})$ profiles among the four cognitive 
statuses are presented in Fig. 2. Abnormal FDG-PET $(\mathrm{F}+)$ accounted for $88.53 \%$ in $\mathrm{AD}$ dementia group $(\mathrm{A}+\mathrm{T}+\mathrm{N}-\mathrm{F}+$ accounted for $22.29 \%$ and $\mathrm{A}+\mathrm{T}+\mathrm{N}+\mathrm{F}+$ accounted for 66.24\%; Fig. 2a). Similarly, in the pMCI group (those who progressed to $\mathrm{AD}$ dementia during at least 2 years followup), $\mathrm{F}+$ accounted for $72.82 \%(\mathrm{~A}+\mathrm{T}+\mathrm{N}-\mathrm{F}+$ accounted for $20.65 \%$ and $\mathrm{A}+\mathrm{T}+\mathrm{N}+\mathrm{F}+$ accounted for $52.17 \%$; Fig. 2a). From $\mathrm{CN}$ to $\mathrm{AD}$ dementia, the proportion of $\mathrm{A}+\mathrm{T}+\mathrm{N}+\mathrm{F}+$ was increasing (13.27\% in CN, $19.12 \%$ in sMCI, $52.17 \%$ in pMCI, $66.24 \%$ in AD dementia), whereas the proportion of $\mathrm{A}+\mathrm{T}+\mathrm{N}-\mathrm{F}-$ was decreasing $(51.02 \%$ in $\mathrm{CN}, 34.31 \%$ in sMCI, $4.35 \%$ in pMCI, $5.10 \%$ in AD dementia) (Fig. 2a). Similarly, the $\mathrm{F}+$ groups have a smaller proportion of $\mathrm{CN}$ (9.80\% in $\mathrm{N}$ - group and $6.37 \%$ in $\mathrm{N}+$ group) and a greater proportion of $\mathrm{AD}$ dementia (34.31\% in $\mathrm{N}$ - group and $50.98 \%$ in N+ group) than the F- groups (Fig. 2b). From Fto $\mathrm{F}+$, the proportion of $\mathrm{AD}$ dementia was increasing (6.06 to $34.31 \%$ in $\mathrm{N}$ - group and 8.85 to $50.98 \%$ in $\mathrm{N}+$ group; Fig. 2b). Similar patterns of frequency distributions were depicted when $\mathrm{HVa}$ was used to define the $\mathrm{N}$ measure (see Additional file 3).

\section{Differences in longitudinal clinical outcomes}

Of the 551 individuals, 537 subjects $(95 \mathrm{CN}, 292 \mathrm{MCI}$, and $150 \mathrm{AD}$ dementia; $127 \mathrm{~A}+\mathrm{T}+\mathrm{N}-\mathrm{F}-, 102 \mathrm{~A}+\mathrm{T}+\mathrm{N}-\mathrm{F}+, 112$ $\mathrm{A}+\mathrm{T}+\mathrm{N}+\mathrm{F}-$, and $196 \mathrm{~A}+\mathrm{T}+\mathrm{N}+\mathrm{F}+$ ) had at least one followup (varied from 1 to 8 years). The mean follow-up duration was $2.7 \pm 1.6$ years. Results of the linear mixed effect models for prediction of cognitive decline and brain atrophy over time were demonstrated in Fig. 3. Estimates represent differences in comparisons of $\mathrm{A}+\mathrm{T}+\mathrm{N}-\mathrm{F}+$ vs $\mathrm{A}+\mathrm{T}+\mathrm{N}-\mathrm{F}-$ and $\mathrm{A}+\mathrm{T}+\mathrm{N}+\mathrm{F}+$ vs $\mathrm{A}+\mathrm{T}+\mathrm{N}+\mathrm{F}-$ and $\mathrm{A}+\mathrm{T}+\mathrm{N}-\mathrm{F}+$ vs $\mathrm{A}+\mathrm{T}+\mathrm{N}+\mathrm{F}-$. The significant differences in rates of change in MMSE, RAVLT-immediate-total, MTL volume, and ventricular volume between $\mathrm{F}+$ and $\mathrm{F}-$ in the $\mathrm{A}+\mathrm{T}+\mathrm{N}-$ group were presented in Fig. 3a (all $p$ values $<0.001$ ). Specifically, compared with F- group, F+ group had faster rates of reduction in MMSE [estimate $=-0.064$,

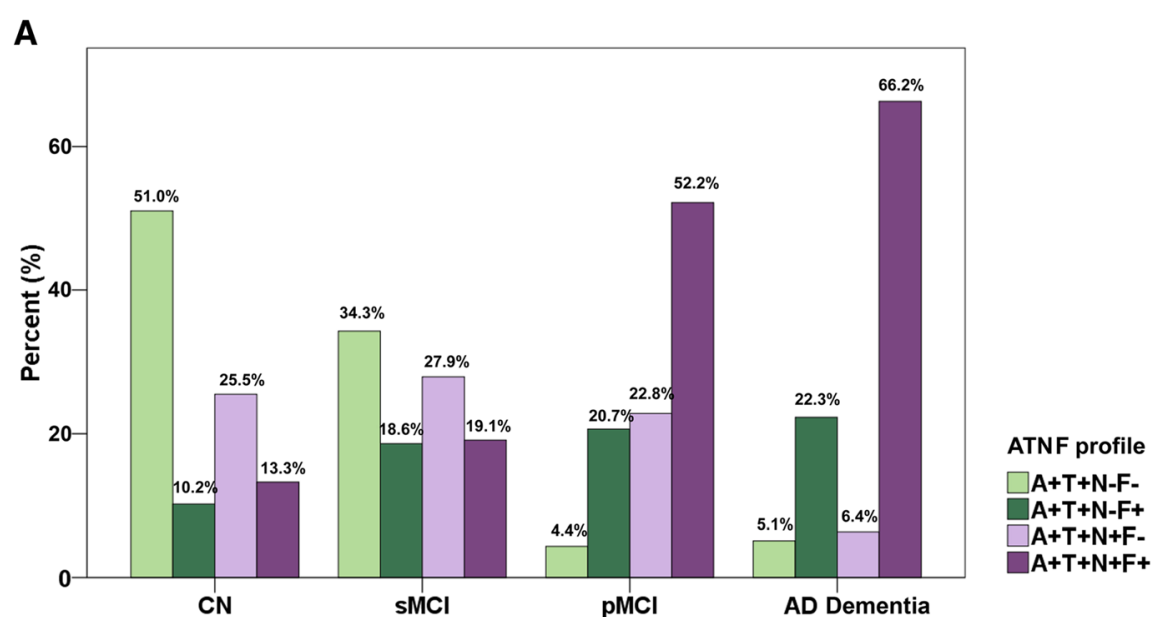

B

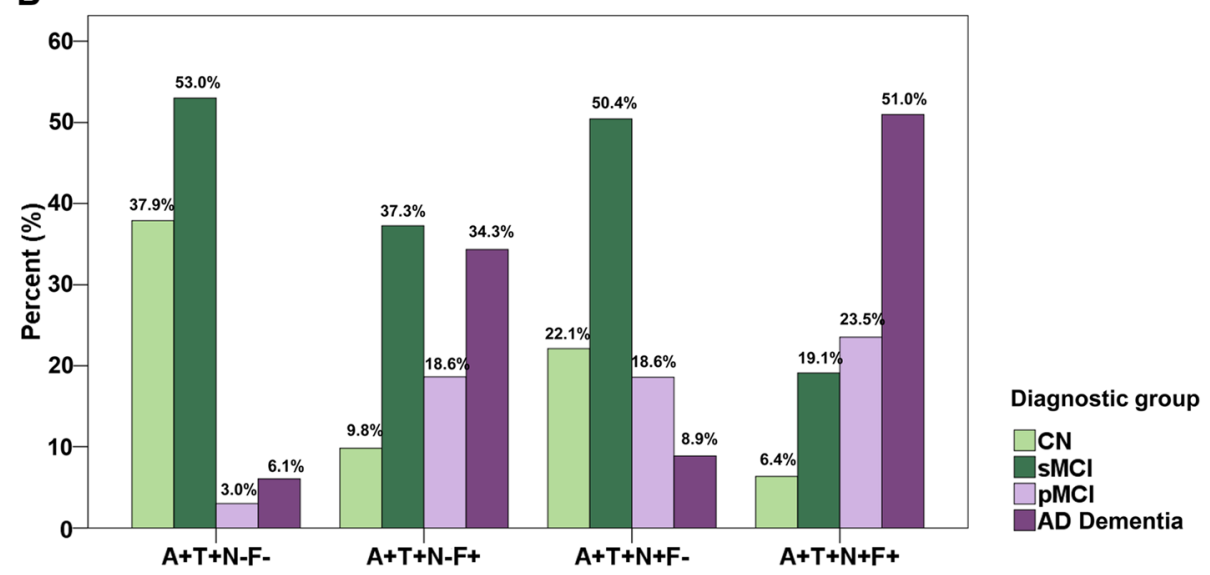

Fig. 2 Frequency distributions of cognitive diagnosis and ATN(F) profiles among different groups. a The distributions of the four ATN(F) profiles in the population with different cognitive states. $\mathbf{b}$ Among the four ATN(F) groups, the various distributions of four cognitive states. Abbreviations: $\mathrm{CN}$, cognitively normal; sMCl, stable mild cognitive impairment; $\mathrm{pMCl}$, progressive mild cognitive impairment; $\mathrm{AD}$, Alzheimer's disease 

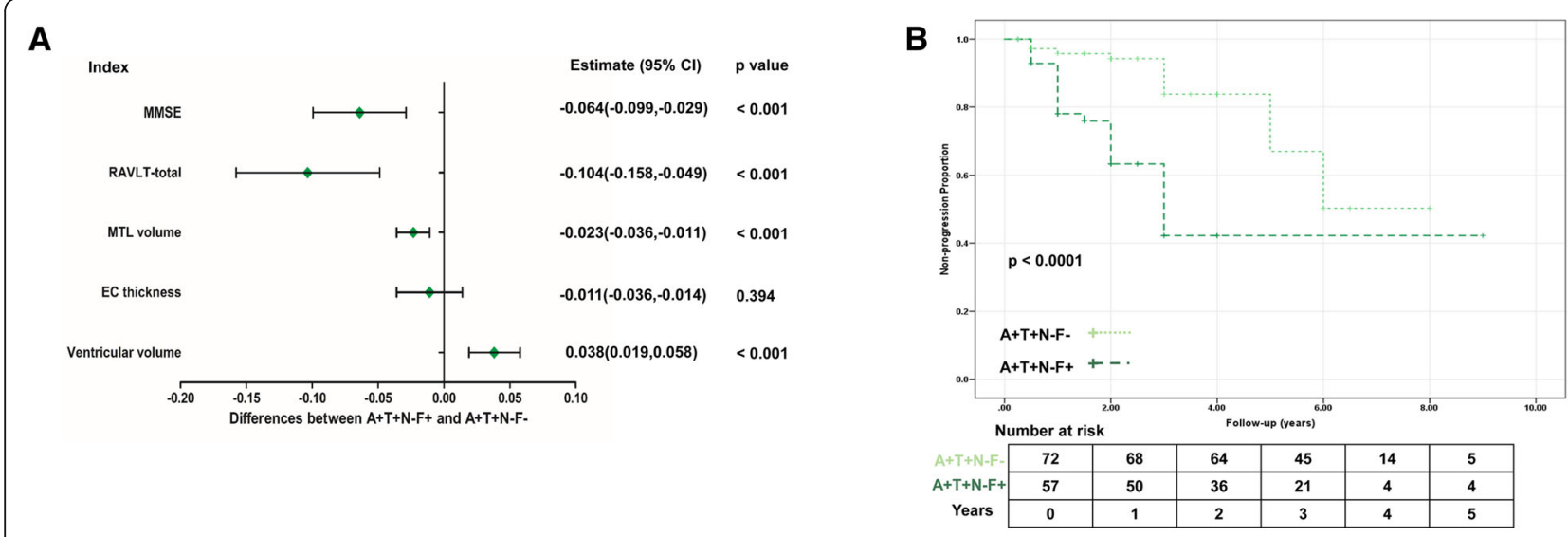

C
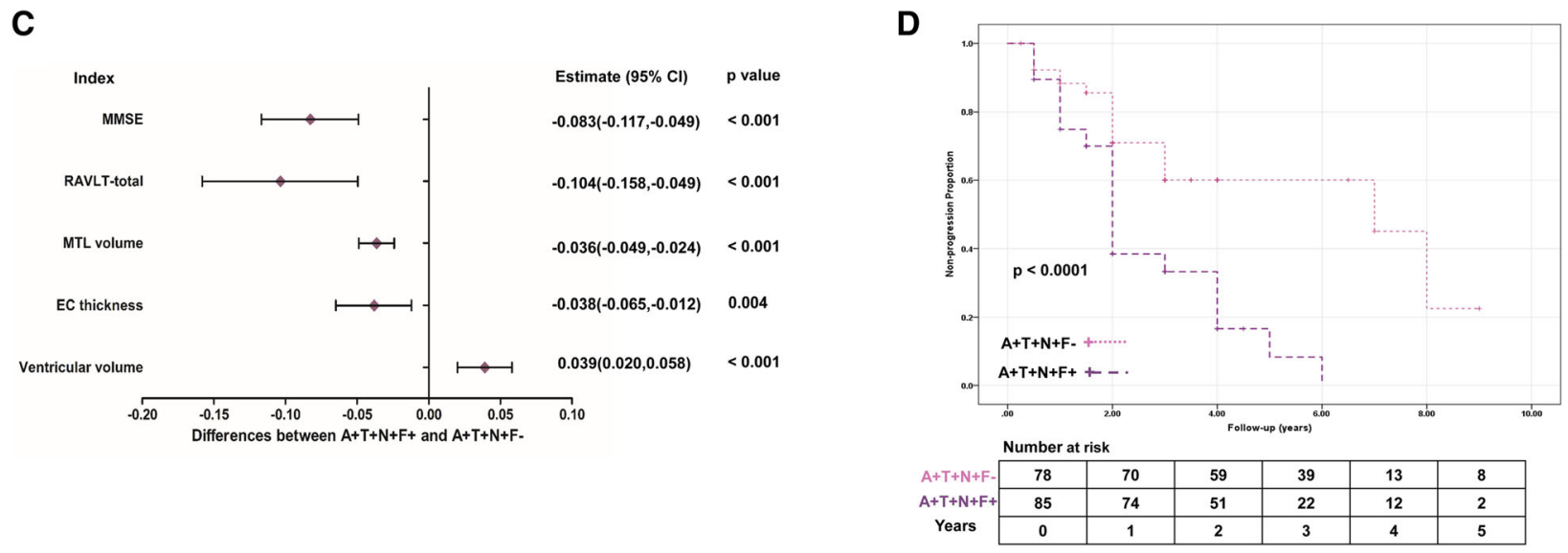

$\mathbf{F}$

$\mathbf{E}$

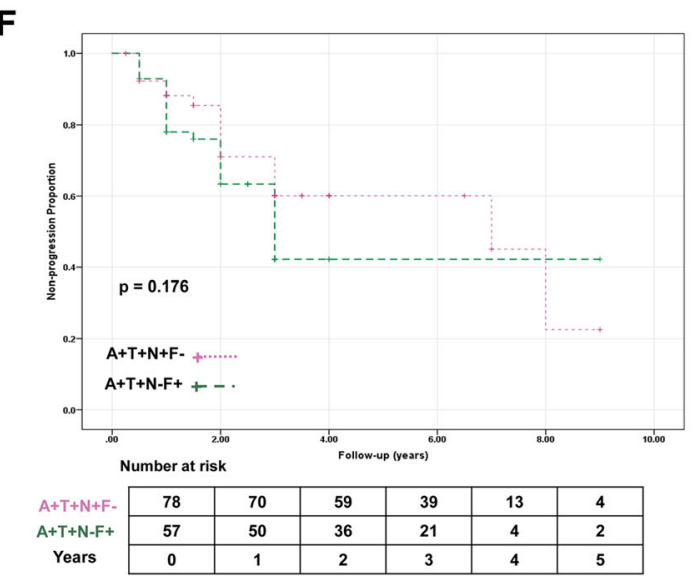

Fig. 3 Clinical progression between every pair of $\mathrm{F}+$ and $\mathrm{F}$ - groups. a, c, e The comparisons of longitudinal changes in cognitive performances and brain structure with $\mathrm{A}+\mathrm{T}+\mathrm{N}+\mathrm{F}-\mathrm{vs} \mathrm{A}+\mathrm{T}+\mathrm{N}-\mathrm{F}$ - revealed in $\mathbf{a}, \mathrm{A}+\mathrm{T}+\mathrm{N}+\mathrm{F}+$ vs $\mathrm{A}+\mathrm{T}+\mathrm{N}+\mathrm{F}$ - in $\mathbf{c}$, and $\mathrm{A}+\mathrm{T}+\mathrm{N}-\mathrm{F}+\mathrm{vs} \mathrm{A}+\mathrm{T}+\mathrm{N}+\mathrm{F}-$ in $\mathbf{e}$. Differences between every pair of $\mathrm{F}+$ and $\mathrm{F}$ - subgroups were demonstrated by estimates with $95 \% \mathrm{Cls}$ and $p$ values. Analyses of cognitive decline were adjusted for age, gender, APOE $\varepsilon 4$, and years of education. Analyses of brain atrophy were adjusted for age, gender, APOE $\varepsilon 4$, and total intracranial volume. $\mathbf{b}, \mathbf{d}$, $\mathbf{f}$ The Kaplan-Meier curves showing cumulative probability of $\mathrm{MCl}$ to AD dementia progression, which were arranged in accordance with the order mentioned above. The small crosses are censored data, and the number of subjects at risk is noted at the bottom of the plot. The unadjusted $p$ values of log-rank test were depicted in the lower left. Abbreviations: MMSE, Mini-Mental State Examination; RAVLT-total, Rey Auditory Verbal Learning Test-immediate-total; MTL, middle temporal volume; EC, entorhinal cortex; MCl, mild cognitive impairment; AD Alzheimer's disease 
$95 \%$ confident interval $(\mathrm{CI})=(-0.099$ to -0.029$), p<0.001]$, RAVLT-immediate-total [estimate $=-0.104,95 \% \mathrm{CI}=$ ( -0.158 to -0.049$), p<0.001$ ] and MTL volume [estimate $=-0.023,95 \% \mathrm{CI}=(-0.036$ to -0.011$), p<0.001]$, and a faster rate of expansion in ventricular volume [estimate $=0.038,95 \% \mathrm{CI}=(0.019$ to 0.058$), p<0.001$ ] .

In $\mathrm{A}+\mathrm{T}+\mathrm{N}+$ groups, the differences in rates of change in MMSE, RAVLT-immediate-total, MTL volume, EC thickness, and ventricular volume between $\mathrm{F}+$ and $\mathrm{F}-$ groups were remarkable with all $p$ values less than 0.005 (Fig. 3c). To be more specific, the F+ group dropped faster than the F- group in MMSE [estimate $=-0.083$, 95\% $\mathrm{CI}=(-0.117$ to -0.049$), p<0.001]$, RAVLT-immediatetotal [estimate $=-0.104,95 \% \mathrm{CI}=(-0.158$ to -0.049$)$, $p<0.001$ ], MTL volume [estimate $=-0.036,95 \% \mathrm{CI}=$ ( -0.049 to -0.024$), p<0.001$ ] and EC thickness [estimate $=-0.038,95 \% \mathrm{CI}=(-0.065$ to -0.012$), p=0.004]$, but increased faster in ventricular volume [estimate $=$ $0.039,95 \% \mathrm{CI}=(0.020$ to 0.058$), p<0.001]$.

We then compared the differences in rates of change in $\mathrm{A}+\mathrm{T}+\mathrm{N}-\mathrm{F}+$ and $\mathrm{A}+\mathrm{T}+\mathrm{N}+\mathrm{F}-$ groups (Fig. 3e). Results demonstrated that the $\mathrm{N}-\mathrm{F}+$ group dropped faster than the $\mathrm{N}+\mathrm{F}-$ group in MMSE [estimate $=-0.049,95 \% \mathrm{CI}=$ ( -0.089 to -0.010$), p=0.014]$, RAVLT-immediate-total [estimate $=-0.080,95 \% \mathrm{CI}=(-0.142$ to -0.019$), p=$ 0.010 ], and MTL volume [estimate $=-0.020,95 \% \mathrm{CI}=$ $(-0.035$ to -0.007$), p=0.004]$, however increased faster in ventricular volume [estimate $=0.041,95 \% \mathrm{CI}=(0.019$ to 0.063$), p<0.001$ ].

When HVa was used to define the "N" biomarker, there were 217 subjects $(35 \mathrm{CN}, 136 \mathrm{MCI}$, and $46 \mathrm{AD}$ dementia; $68 \mathrm{~A}+\mathrm{T}+\mathrm{N}-\mathrm{F}-, 32 \mathrm{~A}+\mathrm{T}+\mathrm{N}-\mathrm{F}+, 37 \mathrm{~A}+\mathrm{T}+\mathrm{N}+\mathrm{F}-$, and 80 $\mathrm{A}+\mathrm{T}+\mathrm{N}+\mathrm{F}+$ ) available for longitudinal analysis. The almost similar results were revealed (see Additional file $4 \mathrm{~A}, \mathrm{C}, \mathrm{E})$.

\section{Prediction of disease progression in $\mathrm{MCl}$ individuals} Of the $292 \mathrm{MCI}$ patients $(72 \mathrm{~A}+\mathrm{T}+\mathrm{N}-\mathrm{F}-, 57 \mathrm{~A}+\mathrm{T}+\mathrm{N}-\mathrm{F}+$, $78 \mathrm{~A}+\mathrm{T}+\mathrm{N}+\mathrm{F}-$, and $85 \mathrm{~A}+\mathrm{T}+\mathrm{N}+\mathrm{F}+), 129$ progressed to $\mathrm{AD}$ dementia. In $\mathrm{A}+\mathrm{T}+\mathrm{N}-$ group, the $\mathrm{KM}$ curve indicated that the MCI patients who were classified in the F+ group had a higher risk of progression to $\mathrm{AD}$ dementia than those in the F- group ( $p_{\text {log-rank }}<0.0001$; Fig. $\left.3 \mathrm{~b}\right)$. Cox regression model adjusted for age, gender, educational level, and $A P O E \varepsilon 4$ status showed a robust result with hazard ratio $(\mathrm{HR})=4.08,95 \% \mathrm{CI}=(1.96-8.48)$. In $\mathrm{A}+\mathrm{T}+\mathrm{N}+$ group, the result was similar. MCI patients with reduced FDG-PET uptake were more likely to progress to $\mathrm{AD}$ dementia with $\mathrm{HR}=2.47,95 \% \mathrm{CI}=(1.55-3.93)$ than those without significantly impaired brain glucose metabolism $\left(p_{\text {log-rank }}<0.0001\right.$; Fig. $\left.3 d\right)$. Compared with $\mathrm{N}+\mathrm{F}-$ group, $\mathrm{N}-\mathrm{F}+$ group showed no significantly increased risk of $\mathrm{AD}$ dementia conversion with $\mathrm{HR}=1.53,95 \% \mathrm{CI}=(0.89$ 2.64 ), and $p_{\text {log-rank }}=0.176$ (Fig. 3f).
When HVa was used to define the "N" biomarker, of the $136 \mathrm{MCI}$ patients $(45 \mathrm{~A}+\mathrm{T}+\mathrm{N}-\mathrm{F}-, 22 \mathrm{~A}+\mathrm{T}+\mathrm{N}-\mathrm{F}+$, $27 \mathrm{~A}+\mathrm{T}+\mathrm{N}+\mathrm{F}-$, and $42 \mathrm{~A}+\mathrm{T}+\mathrm{N}+\mathrm{F}+), 55$ participants progressed to $\mathrm{AD}$ dementia. In $\mathrm{A}+\mathrm{T}+\mathrm{N}-$ group, $\mathrm{MCI}$ patients in the $\mathrm{F}+$ group had much higher rates of progression to $\mathrm{AD}$ dementia than those in the $\mathrm{F}$ - group $\left(p_{\text {log-rank }}=0.018\right.$; see Additional file $\left.4 \mathrm{~B}\right)$. However, the result of multi-adjusted Cox regression was not statistically significant with $\mathrm{HR}=2.40,95 \% \mathrm{CI}=(0.94-6.13)$. In $\mathrm{A}+\mathrm{T}+\mathrm{N}+$ group, the result was similar with significant $p$ value $\left(p_{\text {log-rank }}=0.019\right)$, adjusted HR of 1.94, and 95\% CI of $0.88-4.27$ (see Additional file 4D). Compared with the $\mathrm{N}+\mathrm{F}-$ group, the $\mathrm{N}-\mathrm{F}+$ group showed no increased risk of $\mathrm{AD}$ dementia conversion with $p_{\text {log-rank }}=0.320$ and $\mathrm{HR}=1.38,95 \% \mathrm{CI}=(0.47-4.07)$ (see Additional file 4F).

\section{Clinical relevance and potential differences of using CSF T-tau vs HVa vs FDG-PET hypometabolism as " $\mathrm{N}$ "}

Reduced brain FDG-PET metabolism showed strong relevance with cognitive decline measured by MMSE [estimate $=0.151,95 \% \mathrm{CI}=(0.114$ to 0.188$), p<0.001$ ], MTL atrophy [estimate $=0.035,95 \% \mathrm{CI}=(0.017$ to 0.053$)$, $p=0.001$ ], and ventricular volume expansion [estimate $=-0.053,95 \% \mathrm{CI}=(-0.079$ to -0.027$), p<0.001]$. In comparison, atrophic HV seen on MRI was correlated with a drop in MMSE score [estimate $=0.038,95 \% \mathrm{CI}=$ (0.008 to 0.068), $p=0.014$ ] and $\mathrm{EC}$ atrophy [estimate $=$ $0.046,95 \% \mathrm{CI}=(0.013$ to 0.079$), p=0.007]$. Elevated CSF T-tau was related to MTL atrophy [estimate $=-0.006$, 95\% $\mathrm{CI}=(-0.011$ to -0.001$), p=0.019]$ and large ventricular volume [estimate $=0.015,95 \% \mathrm{CI}=(0.009$ to 0.023 ), $p<0.001$ ] (see Additional file $5 \mathrm{~A}$ ).

A total of $279 \mathrm{MCI}$ individuals were included in the KM analysis. In detail, 148 patients were T-tau $(+), 69$ were HVa (+), and 62 were FDG-PET (+), of which 91/35/36 progressed to $\mathrm{AD}$ dementia eventually. We failed to detect the significant differences of clinical progression among these three groups (see Additional file 5B).

\section{Discussion}

The primary finding is that cognitive decline and brain atrophy in $\mathrm{A}+\mathrm{T}+$ individuals with reduced FDG-PET brain metabolism are much faster than that in the individuals without significantly impaired FDG-PET uptake. Moreover, MCI patients with diminished FDG-PET have much higher rates of progression to AD dementia. Therefore, it is recommended to treat FDG-PET as an independent biomarker for the ATN(F) framework system.

Individuals with abnormal FDG-PET accounted for 88.53\% of all the participants in $\mathrm{AD}$ dementia group and accounted for $72.82 \%$ in the pMCI group (those who progressed to $\mathrm{AD}$ dementia during at least 2 years 
follow-up). We also discovered that the proportion of $\mathrm{A}+\mathrm{T}+\mathrm{N}+\mathrm{F}+$ was increasing $(13.27 \%$ in $\mathrm{CN}, 19.12 \%$ in sMCI, $52.17 \%$ in pMCI, $66.24 \%$ in AD dementia) and the proportion of $\mathrm{A}+\mathrm{T}+\mathrm{N}-\mathrm{F}$ - was decreasing $(51.02 \%$ in $\mathrm{CN}, 34.31 \%$ in sMCI, $4.35 \%$ in pMCI, $5.10 \%$ in $\mathrm{AD}$ dementia) from $\mathrm{CN}$ to $\mathrm{AD}$ dementia. The above results suggest that individuals with diminished glucose metabolism measured by PET are more likely to progress to $\mathrm{AD}$ or to be $\mathrm{AD}$. Diminished glucose uptake in the hippocampus, parieto-temporal cortex, and/or posterior cingulate cortex has been repeatedly shown by FDGPET in early $\mathrm{AD}$ [12] and/or MCI or no cognitive impairment before progression to $\mathrm{AD}$ dementia [13]. However, the sensitivity of FDG-PET index in our analysis only reaches about $72.82 \%$ in patients with pMCI, which is a rather low figure as compared to more sound volume of interest tools. More sensitive alternative choices tracking FDG-PET hypometabolism such as the Support Vector Machine model-based analysis need to be considered in the future studies [14, 15]. Similarly, reduced FDG-PET accounted for a relatively large proportion of $\mathrm{AD}$ dementia (34.31\% in $\mathrm{N}$ - group and $50.98 \%$ in $\mathrm{N}+$ group). From $\mathrm{F}-$ to $\mathrm{F}+$, the proportion of AD dementia increased in both $\mathrm{N}-$ and $\mathrm{N}+$ groups. These results were in line with the previous findings that $\mathrm{AD}$ subjects were more inclined to have reduced brain FDG uptake on PET [16-21].

Longitudinally, we used cognitive scales and MRI scans to investigate declines in brain function (cognitive function reductions) and structure (brain volume loss). MMSE scale, commonly believed to reflect the overall cognitive function and predict $\mathrm{MCI}$ to $\mathrm{AD}$ dementia progression [22], was chosen in our analysis. We also chose RAVLT to reflect psychological function in that word list learning is a predictor of conversion compared to other neuropsychological tests [23-26]. Consistent with our expectations and prior published results [27], our analysis discovered that individuals with lower FDGPET metabolism had worse cognitive performances (scored lower at baseline and dropped faster over time on the two scales), hinting that diminished FDG on PET predicted or accelerated cognitive decline. Longitudinal FDG-PET findings have also suggested that reductions in hippocampal glucose uptake during normal aging can predict cognitive decline years in advance of clinical $\mathrm{AD}$ diagnosis [12]. The two scales are commonly used in evaluating the severity of cognitive impairment. The positive associations of reduced FDG-PET with these two scales could help us get a better understanding of the predictive value of FDG-PET.

Moreover, reduced FDG-PET was associated with reduced sizes of brain structures (smaller volumes at baseline and faster shrunk MTL volume and EC thickness longitudinally) and expanded ventricular volume.
Cerebral atrophy typically starts from the MTL and limbic areas, spreads to parietal association areas, and finally progresses to frontal and primary cortices [28]. The pattern of hypometabolism in AD is that the posterior cingulate cortex is the first area affected, followed by the parieto-temporal areas and then by the frontal regions [29]. It was traditionally believed that cortical atrophy in $\mathrm{AD}$ showed a trajectory that markedly overlapped that of brain glucose metabolism [30]. However, recent studies support that diminished cerebral metabolic rate of glucose (CMRglu) measured by PET precedes cognitive decline and gray matter atrophy measured by MRI [31-36]. Among the three encephalic regions closely related to AD development in our analysis, the integrity of MTL is vital for memory function [37] and decreased MTL metabolism might be a specific marker of subclinical changes in cognition in preclinical AD [38]. Furthermore, reduced FDG uptake in EC is a known feature of $\mathrm{AD}$ $[32,39]$. De Leon et al. showed that in healthy elderly subjects, reduction in cerebral glucose metabolism in EC predicted memory decline and temporal cortex metabolic reductions [21]. Our study suggests that lower FDGPET predicts or accelerates brain atrophy, which is in line with the previous findings [16-21]. Brain glucose metabolism detected by PET is a potentially promising predictor for cerebral matter loss in AD, which could be employed as a valuable tool in clinical settings or scientific researches.

Individuals with $\mathrm{MCI}$ are a target population for evaluating very early treatment interventions for $\mathrm{AD}$ since they are at an intermediate stage between normal cognitive function and AD dementia, and are at higher risk of cognitive decline than healthy older individuals [13]. Several previous FDG-PET studies on MCI have focused on patients with clear-cut memory deficits (i.e., amnesic $\mathrm{MCI})$ that were at high risk of developing $\mathrm{AD}$ dementia [40]. Our KM analysis indicates that the MCI patients who are labeled as $\mathrm{A}+\mathrm{T}+\mathrm{F}+$ (with $\mathrm{N}+$ or $\mathrm{N}-$ ) have much higher rates of progression to $\mathrm{AD}$ dementia than $\mathrm{A}+\mathrm{T}+\mathrm{F}$ -. This might give us a hint that reduced FDG-PET may increase the probability of progression from $\mathrm{MCI}$ to $\mathrm{AD}$ dementia, which was exactly concordant with previous reports which showed that FDG-PET was a very sensitive measure for predicting conversion to $\mathrm{AD}$ dementia in patients with MCI [13], [41, 42].

In this study, CSF T-tau and adjusted HV were used as the "N" biomarkers, from which similar results were obtained. According to analyses, separating FDG-PET from the previous " $\mathrm{N}$ " biomarkers and further building the $\operatorname{ATN}(\mathrm{F})$ framework is necessary and well-founded. In the recently proposed biological definition of $\mathrm{AD}$, the "N" represents a non-specific biomarker of neurodegeneration or neural injury, including CSF T-tau, atrophic brain structures seen on MRI, and FDG hypometabolism 
[1]. These three biomarkers may have discordances. CSF T-Tau probably indicates the intensity of neuronal injury at a given time point, MRI reflects cumulative loss and shrinkage of the neuropil, while FDG-PET conventionally reflects both cumulative loss of neuropil, loss of synapse and functional impairment of the neurons. In this study, the clinical relevance and potential differences of the above three "N" biomarkers were compared, and it is found that brain FDG-PET hypometabolism showed significant correlations with cognitive decline and brain atrophy. Additionally, all of the three biomarkers demonstrated a high correlation with increased risk of $\mathrm{AD}$ dementia conversion; however, the differences are not statistically significant. All these results suggest that FDG-PET may more indicative than the other two "N" biomarkers.

The generated results support the hypothesis that diminished FDG-PET should be re-considered as an independent biomarker. Actually, FDG hypometabolism is a summation of multiple biological processes, but not just neuronal hypometabolism and neurodegeneration. A recent review deems that the diminished uptake of FDG in the AD brain might point to a vascular deficit, specifically, impaired blood-brain barrier (BBB) function. Mechanically speaking, brain uptake of FDG depends on the glucose transporter 1 (GLUT1) [43, 44], which is only expressed on the endothelium of BBB. So, FDG hypometabolism might be a manifestation of BBB breakdown, which is regarded as an early biomarker of cognitive dysfunction that independent of $A \beta$ and tau [45]. Moreover, accumulating publications reported that GLUT1 levels are substantially reduced in AD brain microvessels [46-49]. There is also a recent study indicated that it should be the astrocytes, instead of neurons, to be recognized as the contributor to the FDG signal [6]. In a word, the mechanism of action of FDG-PET is indeed much more complex than existing understanding, and FDG-PET hypometabolism should not be obtrusively classified as a "N" biomarker. This re-classification proposed in the present study may be of great significance to the diagnosis and treatment of patients with $\mathrm{AD}$ because it highlights the potential of FDG uptake to identify the therapeutic window before irreversible neurodegenerative attacks.

This study had limitations. Firstly, dichotomizing each biomarker might conceal an underlying continuum. With four different biomarkers employed, the classification error rate increased compared to a situation where only a single biomarker is used. Secondly, the CSF samples available for longitudinal analysis was insufficient, especially when the population was divided into four groups, which may limit the statistical power to detect longitudinal changes. Lastly, the sensitivity of FDG-PET index in patients with MCI due to AD was rather low, so automatic tools for the detection of
Alzheimer-related hypometabolic pattern with high reliability and generalizability are in command.

\section{Conclusions}

Taken together, the findings, as set forth, from the very study, suggest that $\mathrm{A}+\mathrm{T}+$ individuals with reduced brain FDG uptake on PET have worse cognition, accelerated brain atrophy and an increased likelihood of progression from $\mathrm{MCI}$ to $\mathrm{AD}$ dementia. It is concluded and recommended to regard FDG-PET as a separate biomarker, which is independent from the "N" biomarkers, in a $\operatorname{ATN}(\mathrm{F})$ framework system. The work could be a complement to completing the ATN descriptive framework.

\section{Additional files}

Additional file 1: Table S1. Characteristics of participants by ATN(F) biomarker classification. (DOCX $20 \mathrm{~kb}$ )

Additional file 2: Plots of ATN(F) group characteristics. (DOCX $226 \mathrm{~kb}$ )

Additional file 3: Frequency distributions of cognitive diagnosis and ATN(F) profiles among different groups. (DOCX 276 kb)

Additional file 4: Clinical progression between every pair of $\mathrm{F}+$ and F- groups. (DOCX 265 kb)

Additional file 5: Comparison of clinical progression between CSF T-tau (+) vs HVa (+) vs FDG-PET (+). (DOCX $1321 \mathrm{~kb})$

\section{Abbreviations}

AD: Alzheimer's disease; ADNI: Alzheimer's disease Neuroimaging Initiative; $A \beta$ : $\beta$-amyloid; BBB: Blood-brain barrier; CDR: Clinical Dementia Rating; Cl: Confidence interval; CMRglu: Cerebral metabolic rate of glucose; CN: Cognitively normal; CSF: Cerebrospinal fluid; EC: Entorhinal cortex; GLUT1: Glucose transporter 1; HVa: Adjusted hippocampal volume; KM: Kaplan-Meier; MCl: Mild cognitive impairment; MMSE: Mini Mental State Examination; MRI: Magnetic resonance image; MTL: Middle temporal lobe; NIA-AA: National Institute on Aging-Alzheimer's Association; PET: Positron emission tomography; pMCl: Progressive MCl; P-tau: Phosphorylated tau; RAVLT-total: Rey Auditory Verbal Learning Test-total; SD: Standard deviation; sMCI: Stable MCl; TIV: Total intracranial volume; T-tau: Total tau

\section{Acknowledgements}

Data collection and sharing for this project was funded by the Alzheimer's Disease Neuroimaging Initiative (ADNI) (National Institutes of Health Grant U01 AG024904) and DOD ADNI (Department of Defense award number W81XWH-12-2-0012). ADNI is funded by the National Institute on Aging, the National Institute of Biomedical Imaging and Bioengineering, and through generous contributions from the following: AbbVie, Alzheimer's Association; Alzheimer's Drug Discovery Foundation; Araclon Biotech; BioClinica, Inc.; Biogen; Bristol-Myers Squibb Company; CereSpir, Inc.; Cogstate; Eisai Inc.; Elan Pharmaceuticals, Inc.; Eli Lilly and Company; Eurolmmun; F. Hoffmann-La Roche Ltd. and its affiliated company Genentech, Inc.; Fujirebio; GE Healthcare; IXICO Ltd.; Janssen Alzheimer Immunotherapy Research \& Development, LLC.; Johnson \& Johnson Pharmaceutical Research \& Development LLC.; Lumosity; Lundbeck; Merck \& Co., Inc.; Meso Scale Diagnostics, LLC.; NeuroRx Research; Neurotrack Technologies; Novartis Pharmaceuticals Corporation; Pfizer Inc.; Piramal Imaging; Servier; Takeda Pharmaceutical Company; and Transition Therapeutics. The Canadian Institutes of Health Research is providing funds to support ADNI clinical sites in Canada. Private sector contributions are facilitated by the Foundation for the National Institutes of Health (www.fnih.org). The grantee organization is the Northern California Institute for Research and Education, and the study is coordinated by the Alzheimer's Therapeutic Research Institute at the University of Southern California. ADNI data are disseminated by the Laboratory for Neuro Imaging at the University of Southern California. 
Data used in the preparation of this article were obtained from the Alzheimer's Disease Neuroimaging Initiative (ADNI) database (adni.loni.usc.edu). As such, the investigators within the ADNI contributed to the design and implementation of ADNI and/or provided data but did not participate in analysis or writing of this report. A complete listing of ADNI investigators can be found at: http://adni.loni.usc.edu/wp-content/uploads/how_to_apply/

ADNI_Acknowledgement_List.pdf.

\section{Authors' contributions}

JTY conceptualized the study, analyzed and interpreted the data, and drafted and revised the manuscript. YNO, WX, and JQL analyzed and interpreted the data, drafted and revised the manuscript, did the statistical analysis, and prepared all the figures. CM, QD, and LT interpretation of the data and revision of the manuscript. All authors contributed to the writing and revisions of the paper and approved the final version. Data used in the preparation of this article were obtained from the Alzheimer's Disease Neuroimaging Initiative (ADNI) database (adni.loni.usc.edu). As such, the investigators within the ADNI contributed to the design and implementation of ADNI and/or provided data but did not participate in analysis or writing of this report.

\section{Funding}

This study was supported by grants from the National Key R\&D Program of China (2018YFC1314700), National Natural Science Foundation of China (91849126, 81571245, and 81771148), Shanghai Municipal Science and Technology Major Project (No.2018SHZDZX01) and ZHANGJIANG LAB, Tianqiao and Chrissy Chen Institute, and the State Key Laboratory of Neurobiology and Frontiers Center for Brain Science of Ministry of Education, Fudan University.

\section{Availability of data and materials}

The dataset generated and analyzed in the current study is available from the corresponding author on reasonable request.

\section{Ethics approval and consent to participate}

The study was approved by institutional review boards of all participating institutions, and written informed consent was obtained from all participants or their guardians according to the Declaration of Helsinki (consent for research).

\section{Consent for publication}

Not applicable.

\section{Competing interests}

The authors declare that they have no competing interests.

\section{Author details}

'Department of Neurology, Qingdao Municipal Hospital, Qingdao University, Qingdao, China. ${ }^{2}$ Department of Neurology and Institute of Neurology, Huashan Hospital, Shanghai Medical College, Fudan University, 12th Wulumuqi Zhong Road, Shanghai 200040, China.

\section{Received: 6 March 2019 Accepted: 12 June 2019}

Published online: 29 June 2019

\section{References}

1. Jack CR Jr, Bennett DA, Blennow K, Carrillo MC, Dunn B, Haeberlein SB, et al. NIA-AA research framework: toward a biological definition of Alzheimer's disease. Alzheimers Dement. 2018:14:535-62.

2. McKhann GM, Knopman DS, Chertkow H, Hyman BT, Jack CR Jr, Kawas CH, et al. The diagnosis of dementia due to Alzheimer's disease: recommendations from the National Institute on Aging-Alzheimer's Association workgroups on diagnostic guidelines for Alzheimer's disease. Alzheimers Dement. 2011;7:263-9.

3. Jack CR Jr, Albert MS, Knopman DS, McKhann GM, Sperling RA, Carrillo MC, et al. Introduction to the recommendations from the National Institute on Aging-Alzheimer's Association workgroups on diagnostic guidelines for Alzheimer's disease. Alzheimers Dement. 2011;7:257-62

4. Minati L, Edginton T, Bruzzone MG. Giaccone G current concepts in Alzheimer's disease: a multidisciplinary review. Am J Alzheimers Dis Other Dement. 2009;24:95-121.
5. Sperling RA, Aisen PS, Beckett LA, Bennett DA, Craft S, Fagan AM, et al. Toward defining the preclinical stages of Alzheimer's disease: recommendations from the National Institute on Aging-Alzheimer's Association workgroups on diagnostic guidelines for Alzheimer's disease. Alzheimers Dement. 2011;7:280-92.

6. Zimmer ER, Parent MJ, Souza DG, Leuzy A, Lecrux C, Kim HI, et al. [(18)F]FDG PET signal is driven by astroglial glutamate transport. Nat Neurosci. 2017;20:393-5.

7. Sweeney MD, Montagne A, Sagare AP, Nation DA, Schneider LS, Chui HC, et al. Vascular dysfunction-the disregarded partner of Alzheimer's disease. Alzheimers Dement. 2019;15:158-67.

8. Petersen RC, Aisen PS, Beckett LA, Donohue MC, Gamst AC, Harvey DJ, et al. Alzheimer's disease neuroimaging initiative (ADNI): clinical characterization. Neurology. 2010;74:201-9.

9. Saykin AJ, Shen L, Foroud TM, Potkin SG, Swaminathan S, Kim S, et al. Alzheimer's disease neuroimaging initiative biomarkers as quantitative phenotypes: genetics core aims, progress, and plans. Alzheimers Dement. 2010;6:265-73

10. Jagust WJ, Landau SM, Shaw LM, Trojanowski JQ, Koeppe RA, Reiman EM, et al. Relationships between biomarkers in aging and dementia. Neurology. 2009;73:1193-9.

11. Mormino EC, Betensky RA, Hedden T, Schultz AP, Amariglio RE, Rentz $D M$, et al. Synergistic effect of beta-amyloid and neurodegeneration on cognitive decline in clinically normal individuals. JAMA Neurol. 2014:71:1379-85.

12. Landau SM, Harvey D, Madison CM, Koeppe RA, Reiman EM, Foster NL, et al. Associations between cognitive, functional, and FDG-PET measures of decline in AD and MCI. Neurobiol Aging. 2011;32:1207-18.

13. Landau SM, Harvey D, Madison CM, Reiman EM, Foster NL, Aisen PS, et al. Comparing predictors of conversion and decline in mild cognitive impairment. Neurology. 2010;75:230-8.

14. De Carli F, Nobili F, Pagani M, Bauckneht M, Massa F, Grazzini M, et al. Accuracy and generalization capability of an automatic method for the detection of typical brain hypometabolism in prodromal Alzheimer disease. Eur J Nucl Med Mol Imaging. 2019;46:334-47.

15. Pagani M, Nobili F, Morbelli S, Arnaldi D, Giuliani A, Oberg J, et al. Early identification of $\mathrm{MCl}$ converting to AD: a FDG PET study. Eur J Nucl Med Mol Imaging. 2017:44:2042-52.

16. Mosconi L, De Santi S, Li Y, Li J, Zhan J, Tsui WH, et al. Visual rating of medial temporal lobe metabolism in mild cognitive impairment and Alzheimer's disease using FDG-PET. Eur J Nucl Med Mol Imaging. 2006;33:210-21.

17. Mosconi L, Tsui WH, De Santi S, Li J, Rusinek H, Convit A, et al. Reduced hippocampal metabolism in $\mathrm{MCl}$ and $\mathrm{AD}$ : automated FDG-PET image analysis. Neurology. 2005;64:1860-7.

18. Mosconi L. Brain glucose metabolism in the early and specific diagnosis of Alzheimer's disease. FDG-PET studies in MCl and AD. Eur J Nucl Med Mol Imaging. 2005;32:486-510.

19. Nestor PJ, Fryer TD, Smielewski P, Hodges JR. Limbic hypometabolism in Alzheimer's disease and mild cognitive impairment. Ann Neurol. 2003;54:343-51.

20. De Santi S, de Leon MJ, Rusinek H, Convit A, Tarshish CY, Roche A, et al. Hippocampal formation glucose metabolism and volume losses in $\mathrm{MCl}$ and AD. Neurobiol Aging. 2001;22:529-39.

21. de Leon MJ, Convit A, Wolf OT, Tarshish CY, DeSanti S, Rusinek H, et al. Prediction of cognitive decline in normal elderly subjects with 2[(18)F]fluoro-2-deoxy-D-glucose/poitron-emission tomography (FDG/PET). Proc Natl Acad Sci U S A. 2001;98:10966-71.

22. Arbizu J, Prieto E, Martinez-Lage P, Marti-Climent JM, Garcia-Granero M, Lamet I, et al. Automated analysis of FDG PET as a tool for single-subject probabilistic prediction and detection of Alzheimer's disease dementia. Eur J Nucl Med Mol Imaging. 2013:40:1394-405

23. Tierney MC, Yao C, Kiss A, McDowell I. Neuropsychological tests accurately predict incident Alzheimer disease after 5 and 10 years. Neurology. 2005;64:1853-9.

24. Blacker D, Lee H, Muzikansky A, Martin EC, Tanzi R, McArdle JJ, et al. Neuropsychological measures in normal individuals that predict subsequent cognitive decline. Arch Neurol. 2007;64:862-71.

25. Tabert MH, Manly JJ, Liu X, Pelton GH, Rosenblum S, Jacobs $M$, et al. Neuropsychological prediction of conversion to Alzheimer disease in patients with mild cognitive impairment. Arch Gen Psychiatry. 2006;63: 916-24. 
26. Schmand B, Eikelenboom P, van Gool WA. Value of diagnostic tests to predict conversion to Alzheimer's disease in young and old patients with amnestic mild cognitive impairment. J Alzheimers Dis. 2012;29:641-8.

27. Shokouhi S, Claassen D, Kang H, Ding Z, Rogers B, Mishra A, et al. Longitudinal progression of cognitive decline correlates with changes in the spatial pattern of brain 18F-FDG PET. J Nucl Med. 2013;54:1564-9.

28. Braak H, Braak E. Neuropathological stageing of Alzheimer-related changes Acta Neuropathol. 1991;82:239-59.

29. Chetelat G. Neuroimaging Alzheimer's disease: early diagnosis, monitoring, and mechanism understanding. Med Sci (Paris). 2011;27:193-8.

30. Buckner RL, Snyder AZ, Shannon BJ, LaRossa G, Sachs R, Fotenos AF, et al. Molecular, structural, and functional characterization of Alzheimer's disease: evidence for a relationship between default activity, amyloid, and memory. J Neurosci. 2005;25:7709-17.

31. Ruitenberg A, den Heijer T, Bakker SL, van Swieten JC, Koudstaal PJ, Hofman A, et al. Cerebral hypoperfusion and clinical onset of dementia: the Rotterdam study. Ann Neurol. 2005:57:789-94.

32. Mosconi L, Pupi A, De Cristofaro MT, Fayyaz M, Sorbi S, Herholz K. Functional interactions of the entorhinal cortex: an 18F-FDG PET study on normal aging and Alzheimer's disease. J Nucl Med. 2004;45:382-92.

33. Matsuda H, Kitayama N, Ohnishi T, Asada T, Nakano S, Sakamoto S, et al Longitudinal evaluation of both morphologic and functional changes in the same individuals with Alzheimer's disease. J Nucl Med. 2002:43:304-11.

34. Protas HD, Chen K, Langbaum JB, Fleisher AS, Alexander GE, Lee W, et al. Posterior cingulate glucose metabolism, hippocampal glucose metabolism, and hippocampal volume in cognitively normal, late-middle-aged persons at 3 levels of genetic risk for Alzheimer disease. JAMA Neurol. 2013;70:320-5.

35. Reiman EM, Chen K, Alexander GE, Caselli RJ, Bandy D, Osborne D, et al. Functional brain abnormalities in young adults at genetic risk for late-onset Alzheimer's dementia. Proc Natl Acad Sci U S A. 2004;101:284-9.

36. Bailly M, Destrieux C, Hommet C, Mondon K, Cottier JP, Beaufils E, et al. Precuneus and cingulate cortex atrophy and hypometabolism in patients with Alzheimer's disease and mild cognitive impairment: MRI and (18)F-FDG PET quantitative analysis using FreeSurfer. Biomed Res Int. 2015;2015:583931.

37. Squire LR, Stark CE, Clark RE. The medial temporal lobe. Annu Rev Neurosci. 2004;27:279-306.

38. Vannini P, Hanseeuw B, Munro CE, Amariglio RE, Marshall GA, Rentz DM, et al. Hippocampal hypometabolism in older adults with memory complaints and increased amyloid burden. Neurology. 2017;88:1759-67.

39. Samuraki M, Matsunari I, Chen WP, Yajima K, Yanase D, Fujikawa A, et al. Partial volume effect-corrected FDG PET and grey matter volume loss in patients with mild Alzheimer's disease. Eur J Nucl Med Mol Imaging. 2007;34:1658-69.

40. Petersen RC, Doody R, Kurz A, Mohs RC, Morris JC, Rabins PV, et al. Current concepts in mild cognitive impairment. Arch Neurol. 2001;58:1985-92.

41. Ito K, Fukuyama H, Senda M, Ishii K, Maeda K, Yamamoto $Y$, et al. Prediction of outcomes in mild cognitive impairment by using 18F-FDG-PET: a multicenter study. J Alzheimers Dis. 2015;45:543-52.

42. Ding Y, Sohn JH, Kawczynski MG, Trivedi H, Harnish R, Jenkins NW, et al. A deep learning model to predict a diagnosis of Alzheimer disease by using (18)F-FDG PET of the brain. Radiology. 2019;290:456-64.

43. McDougal DB Jr, Ferrendelli JA, Yip V, Pusateri ME, Carter JG, Chi MM, et al. Use of nonradioactive 2-deoxyglucose to study compartmentation of brain glucose metabolism and rapid regional changes in rate. Proc Natl Acad Sci U S A. 1990;87:1357-61.

44. Sokoloff L, Reivich M, Kennedy C, Des Rosiers MH, Patlak CS, Pettigrew KD, et al. The [14C]deoxyglucose method for the measurement of local cerebral glucose utilization: theory, procedure, and normal values in the conscious and anesthetized albino rat. J Neurochem. 1977;28:897-916.

45. Nation DA, Sweeney MD, Montagne A, Sagare AP, D'Orazio LM, Pachicano $M$, et al. Blood-brain barrier breakdown is an early biomarker of human cognitive dysfunction. Nat Med. 2019;25:270-6.

46. Mooradian AD, Chung HC, Shah GN. GLUT-1 expression in the cerebra of patients with Alzheimer's disease. Neurobiol Aging. 1997;18:469-74.

47. Simpson IA, Chundu KR, Davies-Hill T, Honer WG, Davies P. Decreased concentrations of GLUT1 and GLUT3 glucose transporters in the brains of patients with Alzheimer's disease. Ann Neurol. 1994;35:546-51.
48. Kalaria RN, Harik SI. Reduced glucose transporter at the blood-brain barrie and in cerebral cortex in Alzheimer disease. J Neurochem. 1989:53:1083-8.

49. Horwood N, Davies DC. Immunolabelling of hippocampal microvessel glucose transporter protein is reduced in Alzheimer's disease. Virchows Arch. 1994;425:69-72.

\section{Publisher's Note}

Springer Nature remains neutral with regard to jurisdictional claims in published maps and institutional affiliations.
Ready to submit your research? Choose BMC and benefit from:

- fast, convenient online submission

- thorough peer review by experienced researchers in your field

- rapid publication on acceptance

- support for research data, including large and complex data types

- gold Open Access which fosters wider collaboration and increased citations

- maximum visibility for your research: over $100 \mathrm{M}$ website views per year

At BMC, research is always in progress.

Learn more biomedcentral.com/submissions 